\title{
Environment, Safety, and Health Considerations for a Neutrino Source Based on a Muon Storage Ring
}

\section{J. Donald Cossairt \\ May 2000}

I. Introduction

II. Procedural/Regulatory Matters

A. Environmental Protection Procedural/Regulatory Matters

B. Safety and Health Procedural/Regulatory Matters

III. Occupational Safety During the Construction of the Facility

A. Proton Driver, Target Station, Cooling Region, and Muon Acceleration Linacs

B. Muon Storage Ring

IV. Environmental Protection During Construction

A. Proton Driver, Target Station, Cooling Region, and Muon Acceleration Linacs

B. Muon Storage Ring

V. Occupational Safety During the Operation of the Facility

A. $\quad$ "Ordinary" Occupational Safety Hazards

B. Novel Occupational Safety Hazards

i. $\quad$ Large Scale Use of Cryogens

ii. Ionization Cooling Region

iii. Muon Storage Ring Life Safety (Egress) Considerations

iv. Muon Storage Ring Slope Hazards

VI. Radiological Concerns During Operation of the Facility

A. Proton Driver

i. $\quad$ Prompt Radiation Shielding

ii. Residual Radioactivity of Components

iii. Residual Radioactivity at the Target Station

iv. Airborne Radioactivity

v. Radioactivity in Soil and Groundwater

B. Cooling Stages

C. Muon Acceleration Stages

D. Muon Storage Ring

i. Control of Radiation Dose Due to Neutrinos

ii. Other Radiation Sources

VII. Non-Radiological Environmental Protection Issues During Operation

A. Proton Driver, Target Station, Cooling Region, and Muon Acceleration Linacs

B. Muon Storage Ring

VIII. Summary

Acknowledgments

References 


\section{Introduction}

The Neutrino Source presents a number of challenges in the general area of environment, safety, and health. It is the intent of this paper to identify these challenges and make a preliminary, but not detailed assessment of how they might be addressed and of their potential impact on the project. Some of the considerations which much be taken into account are very similar to those that have been encountered and solved during the construction and operation of other facilities at Fermilab and at similar laboratories elsewhere in the United States and worldwide. Other considerations have not been encountered previously in connection with the construction and operation of accelerator laboratories. These novel issues will require particular attention as such a project proceeds to assure their timely resolution in a manner that is cost-effective and that meets the approval of the public. In this paper, both the conventional and the novel issues are discussed, with more emphasis on the latter. It is concluded here that with adequate planning in the design stages, these problems can be adequately addressed in a manner that merits the support of the Laboratory, the Department of Energy, and the public. An abbreviated version of this paper appears as Chapter 14 in the report of a recent feasibility study (Ho 00) and the figures have come from that work.

\section{Procedural/Regulatory Matters}

The actual design, construction, and operation of the Neutrino Source will have to meet a number of procedural/regulatory milestones in the area of environment, safety, and health to assure timely and continued support of this project by the public and by the Department of Energy. The devotion of early attention to these issues is likely the best way to enhance public support of the project. Requirements in environment, safety and health are currently set forth as a part of Fermilab's Work Smart Standards in Environment, Safety, and Health that are incorporated in the current version of the contract between Universities Research Association and DOE. Currently, the Work Smart Standards are reviewed annually to assure that they adequately address the hazards of the laboratory, including those of any new facility. If changes are necessary they are negotiated with the DOE-FRMI Group and the URA-DOE contract is revised accordingly. These

standards include listings of applicable Federal and State Regulations as well as internally developed policies and national standards (WSS 99).

\section{A. Environmental Protection Procedural/Regulatory Matters}

All DOE activities are subject to the requirements of DOE's regulations for implementing the National Environmental Policy Act (NEPA). First, the project will be the subject of an Environmental Assessment (EA). A review will be done of all possible impacts of this project on the environment and the public. The required analysis is broad in scope and includes societal impacts along with those topics that are more generally associated with environmental protection such as the discharges of pollutants, effects upon wetlands and floodplains, and exposures of people to chemicals and radioactive materials. It will include a review of the alternatives of carrying out the project elsewhere or not at all. This process is centered on the production of a comprehensive document but also includes the participation of the public by methods chosen by DOE. The result of the environmental assessment process is either a Finding of No Significant 
Impact (FONSI) issued by DOE or the conclusion by DOE that the preparation of an Environmental Impact Statement (EIS) is necessary. DOE may well choose to conclude that the preparation of the EIS is required due to the size, scope, cost, or impact on the human environment of the project. The completion of the EIS process results in the issue of a formal notice called a Record of Decision (ROD). The EIS process is generally considered to be an arduous one, but one that can be followed to a successful conclusion stated in the ROD. The preparation of an EIS is certain to be a large task having significant cost, customarily accomplished using external resources. Funds cannot be issued to support such a "line item" project beyond the early conceptual stage prior to the successful completion of the NEPA process.

Other procedural requirements apply in the arena of environmental protection. These will be certainly identified as a part of the NEPA process but early planning may well serve to avert problems later. DOE facilities are generally subject to Federal and State environmental protection regulations promulgated chiefly by the U. S. Environmental Protection Agency (USEPA) and the Illinois Environmental Protection Agency (IEPA), respectively. There are environmental permits to obtain from both state and federal authorities that are likely to be found to apply to this project. Some of these apply during the construction stages, others apply during operations, and some apply during both stages. Somewhat complete discussion will be provided in subsequent sections of this chapter. Permits may be determined to be required to cover such topics as storm water discharges, discharges of cooling water, wetlands mitigation, releases of air pollutants for both non-radioactive pollutants and for radionuclides, and construction in any floodplains. The preparation of these permits is generally straightforward, but must be accomplished with long lead times, typically 180 days, required by the issuing agencies. Early coordination with the project design team should greatly facilitate completion of the associated milestones. Archaeological sites are also located on the Fermilab site that might need further investigation and study prior to the commencement of construction.

\section{B Safety and Health Procedural/Regulatory Matters}

In accordance with the Fermilab's Work Smart Standards, the Laboratory will be required to prepare an assessment of the environment, safety, and health issues associated with this project in the form of a Safety Assessment Document (SAD). Given the size, scope, cost, and novelty of this project, the preparation of a first stage document called a Preliminary Safety Assessment Document (PSAD) is in the best interest of the Laboratory. The purpose of the PSAD is to identify the relevant environmental, safety, and health issues at an early stage and propose how they might be mitigated. The SAD, then, documents the resolution of all the pertinent issues raised by the PSAD. Environmental issues are customarily integrated into the PSAD/SAD process to promote program cohesiveness. Given the scope of this project, it is nearly certain that DOE will review these safety documents by utilizing an external review team composed of both DOE staff and representatives from other DOE facilities. Just prior to facility operation, a readiness review will be conducted in similar fashion using an external review team. DOE has specified a somewhat more rigorous procedure for the conduct of this safety review process in its Orders. The details of the procedures to be followed in the safety review process will be determined by the terms of the contract under which the Laboratory is operated at the time the 
project might proceed. Unlike NEPA assessment activities, PSAD/SAD activities generally begin after funds are issued. Nevertheless, careful consideration of PSAD/SAD in the design can only result in beneficial results.

DOE is presently "self-regulating" in the areas of industrial safety and occupational radiation protection. There is a possibility that during the development of this project, DOE activities might become subject to "external" regulation in these areas, as well as in occupational radiation protection. It is difficult at this time to anticipate the form such external regulation might take or which agencies might participate. This possible development is being monitored closely by senior Fermilab staff and by DOE in order to identify new requirements or procedures that might apply to laboratory activities, including new projects such as the Neutrino Source.

Efforts should be taken at early stages to promote consistency between the conclusions of the NEPA assessment and the safety and health documentation.

\section{Occupational Safety During Construction of the Facility}

A. Proton Driver, Target Station, Cooling Region, and Muon Acceleration Linacs

Figure 1 is a schematic drawing showing the layout of the present conceptual design. These facilities all would be located within the glacial till strata at a distance below the relatively flat surface of the Fermilab site of less than $30 \mathrm{ft}$ (10 meters). The present concepts have these facilities all located at the same approximate elevation. This distance beneath the surface is largely driven by two factors; the need to have convenient interconnections with existing facilities and the need to provide the required amount of prompt radiation (largely neutron) shielding (see below). At this level, the construction is likely to proceed by the standard "cut and fill" method used elsewhere successfully at Fermilab for many years. The standard practices embodied in the Occupational Safety and Health Administration's (OSHA's) regulations on the safety of construction activities would be followed. Particular requirements that address excavations, the provision of applicable personnel protective equipment, coordination of emergency response measures, fire safety, chemical safety, and electrical safety would apply as they have for many years to other civil construction projects on the Fermilab site. It is presumed that provisions for egress of construction workers would be available by means of the numerous entrances being constructed as part of the facility.

During project construction, industrial radiography, a tool commonly used in general industry, is likely to be employed to assure the quality if pipe welds, etc. Such radiographic operations, which typically use radioactive sources of high activity, would need to be conducted in compliance with the pertinent requirements of the State of Illinois in order to control the hazard to personnel of these intense radioactive sources. This has been the standard practice for many years at Fermilab. In the course of construction, other radiation-generating devices such as soil density gauges and media water-content probes might also need to be used. Standard procedures pertaining to such activities will be applied. 


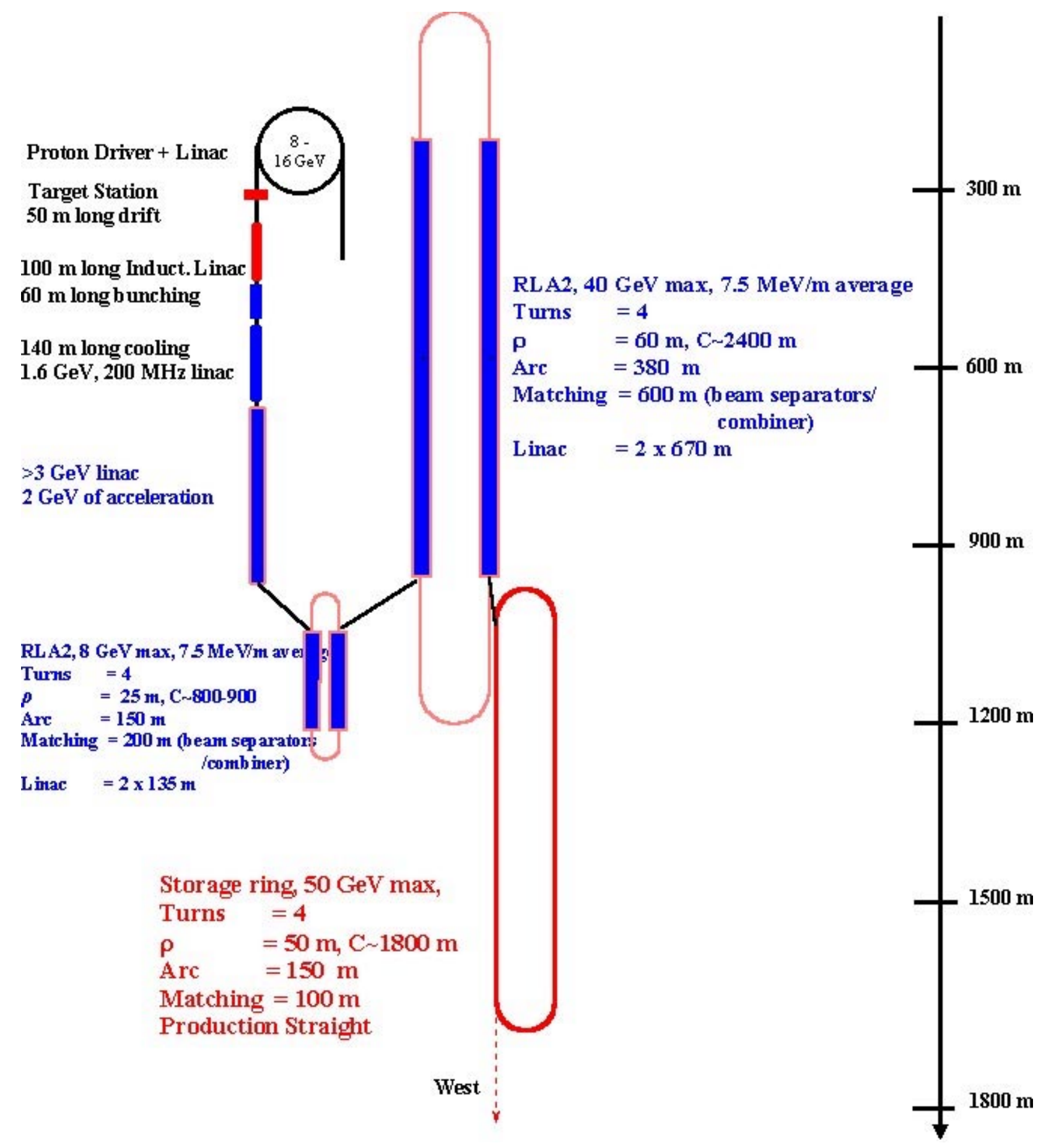

Figure 1 Conceptual layout of reference design for the Neutrino Source considered in this paper. 


\section{B. Muon Storage Ring (MuSR)}

The MuSR would require the excavation of a tunnel through several geologic units; the glacial till, the Silurian (primarily dolomite), the Maquoketa (primarily shale), the Galena/Platteville (primarily dolomite), and the Ancel (primarily sandstone). The general layout of the facility in these geological units is shown in Figure 2. Figure 3 shows details of the lower, western end of the MuSR. While some construction would occur in the glacial till, the vast majority would take place in the bedrock units. All of the bedrock units contain aquifers except for the Galena/Platteville, largely an aquatard. The current benchmark footprint is that of a racetrack with two straight sections 2386 feet ( 727 meters) connected at the ends by semi-circular tunnels of 280 feet (85.3 meter) diameter. Two 70 meter long "near detector halls" are included. The interiors of these tunnels are planned to have cross sections comparable to that of existing beam line and accelerator enclosures.

Unlike the other components of this facility, the excavation of the race-track like tunnel would occur over a length of 2662 feet (811 meters) at an angle of 13.16 degrees with the horizontal (downward, toward the west). While the eastern (uphill) end would be accessible by conventional means of egress, the western (downhill) end, would be located approximately 630 feet (192 meters) below the surface. In addition to the safety requirements pertaining to construction activities, Federal regulations pertaining to underground operations (e.g., "mining" activities) come into play. Solutions to these issues are being developed to address similar challenges encountered in the excavation for the NuMI project. These include the standard concerns about tunneling safety and material movement as the tunneling proceeds. The choice of construction methods between the use of a Tunnel Boring Machine (TBM) or the employment of drilling and blasting methods will most likely be one of economics or availability. However, either alternative has associated occupational safety considerations. Provisions for emergency response including underground rescues will be needed. The Laboratory's experience with NuMI should be most useful. It is expected that as the latter project proceeds, the Laboratory's experience with operations of this type will continue to develop.

Given the location within several major aquifers, and the downward slope, it is clear that stringent measures must be taken to prevent flooding both during the construction period and thereafter. Likewise, the downward slope, about four times that of the NuMI tunnel, requires careful planning to include provisions for adequate protection against uncontrolled, hazardous downward movements of equipment and materials. These measures probably should be passive rather than active in nature and in harmony with actions taken to address this same condition with respect to environmental protection considerations (see Section IV.B). While such control measures are well within those encountered in mining operations elsewhere, they should be addressed at an early stage. The existence of the steep slope also needs to be carefully considered in planning for emergency rescue operations that conceivably could be needed during construction. 


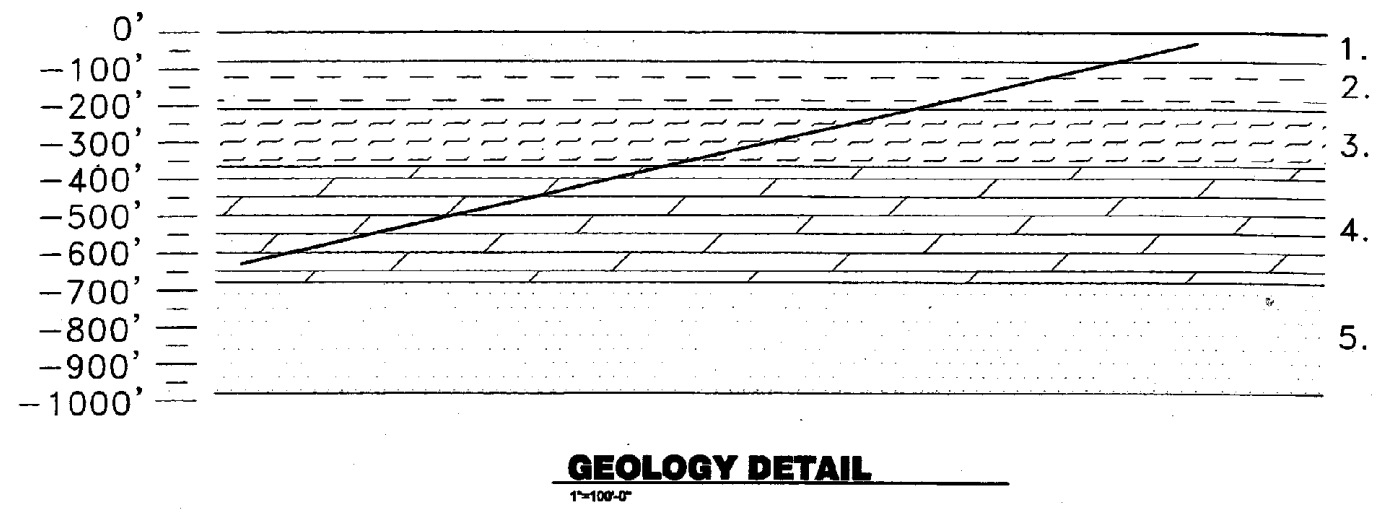

1. GLACIAL TILL - NON-AQUIFER

2. $-\overline{-}-\overline{-}-$ SILURIAN GROUP - AQUIFER (PRIMARILY DOLOMITE)

3. $:=\Xi \Xi \approx=$ MAQUOKETA GROUP - AQUIFER (PRIMARILY SHALE)

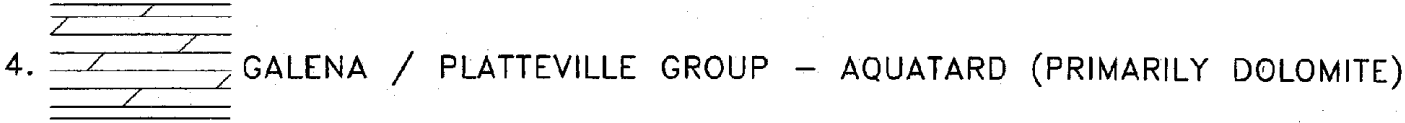

5. ANCEL GROUP - AQUIFER (PRIMARILY SANDSTONE)

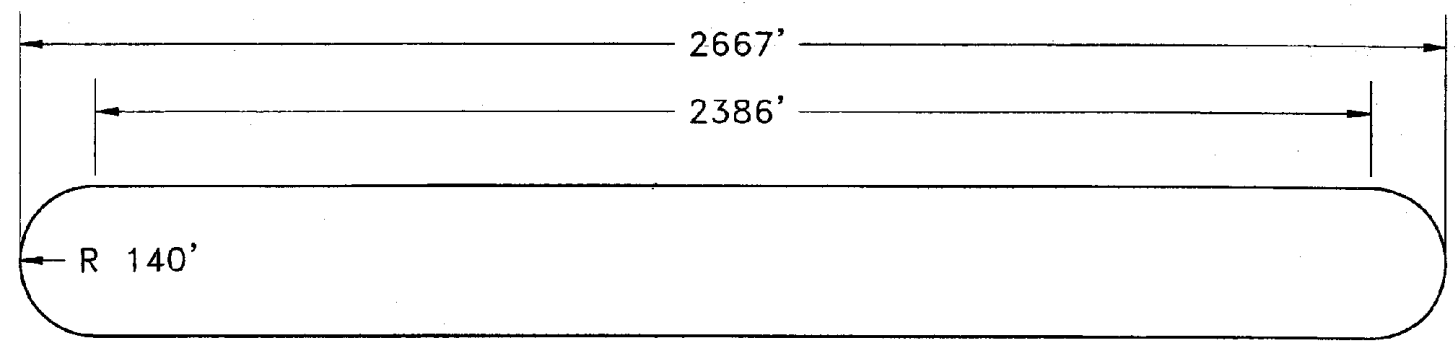

CE 2.1 LATTICE PLAN

\begin{tabular}{|lcc|}
\hline ORIENTATIONE & & \\
\hline NAME & AZIMUTH & VERT. ANGLE \\
PALO ALTO CA. & $271-20^{\prime}-42.27 "$ & $-13-09^{\prime}-26.99^{\prime \prime}$ \\
\hline
\end{tabular}

Figure 2 Conceptual layout of the Muon Storage Ring (MuSR) in the various geological units. The orientation is constrained to direct the neutrinos toward Palo Alto, CA. 

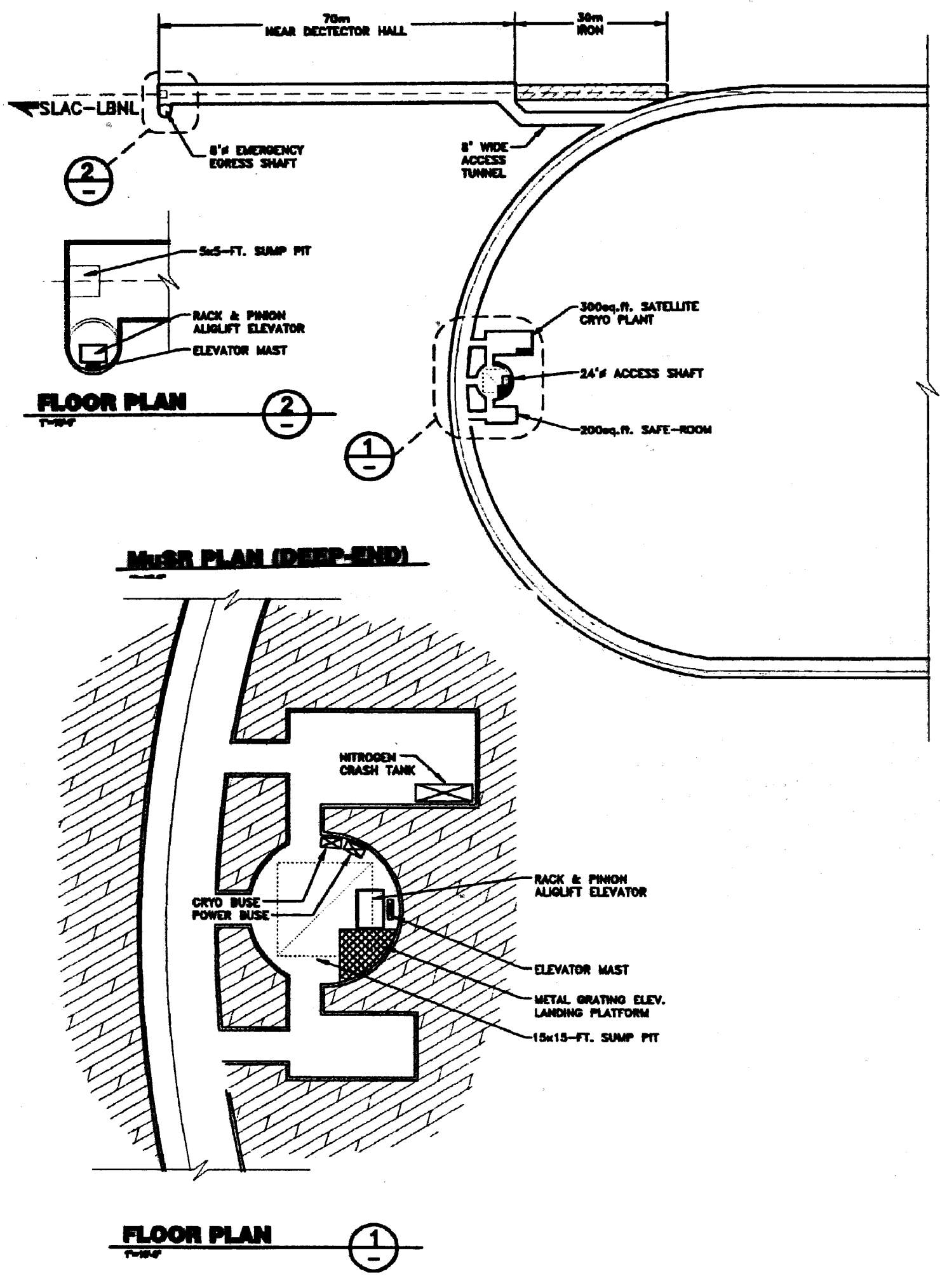

Figure 3 Conceptual design of the lower, western end of the MuSR showing, on different scales, the lower "near detector hall", the various access shafts, and the provisions for egress and safe refuge. 


\section{Environmental Protection During the Construction of the Facility}

A. Proton Driver, Target Station, Cooling Region, and Muon Acceleration Linacs

Construction activities in portions of the facility are similar to those encountered elsewhere at Fermilab, as discussed in Section III. Erosion control measures similar to those in practice for a number of years will be employed in accordance with good engineering practice and Federal and State regulations. Dust from any spoil piles must be kept under control. Likewise, a stormwater management plan will need to be developed. If 5 acres ( 2.0 hectares) or more of land surface are impacted by the construction, a National Pollutant Discharge Elimination System (NPDES) Stormwater Permit for construction will be needed which will include specific actions which must be followed during the construction period. The usual precautions to prevent pollution from spills of regulated chemicals from the construction equipment will need to be taken. Noise from construction activities is not expected to be significantly larger than that associated with normal civil construction activities in the vicinity of Fermilab.

The NEPA process described in Section II.A should result in a determination of the impact of the project on wetlands and or floodplains. A general description of how any identified effects will be mitigated will have been developed. For example, if more than 3 acres of wetlands are identified, it may be necessary for compensatory man-made wetlands to be created. Rearrangement/enlargement of the Fermilab pond system might prove to be necessary to compensate for possible interference with floodplains. It may be especially important to demonstrate adequate care for floodplains due to significant local public concerns about flood prevention.

\section{B. Muon Storage Ring (MuSR)}

The tunneling in the bedrock units will result in the removal of a considerable volume of rock. The experience soon to be gained with the NuMI project may be most useful. The management of the spoil is a major issue that must be addressed and provisions for its proper stockpiling provided. In particular, concerns about dust may be more severe for this material, largely pulverized rock. The duration of this storage may be temporary for the spoil that is of marketable quality and longer for that requires reuse at Fermilab or disposal. This should be carefully planned in accordance with Fermilab's longstanding tradition of placing high importance on aesthetic issues.

Tunneling activities can generate considerable noise and vibration. At this time it is not known if blasting techniques will be employed. Should they be used, quantitative standards apply to the amplitude of the vibrations that are allowable at the surface. Noise exposure, both occupational and to the public at the site boundary, could be an issue that needs to be addressed. The experience of the NuMI project, including quantitative measurements of vibration amplitudes during its construction, will be helpful here. 
The storm water management plan will need to take into account any releases of groundwater generated in the course of "dewatering" the tunnel. Careful hydrogeologic studies need to be performed to understand the interplay of the construction of the project with the various aquifers. This must be done to establish with certainty that the construction activities will not cause significant perturbations of the local individual and municipal water supplies, either in quality or in quantity. The present conceptual drawings show the Galena/Platteville unit to be included in the excavation. The exact depth of the top of the aquatard of the Galena/Platteville unit is known to be nonuniform across the Fermilab site. However, the location of this boundary is not known accurately at all locations. Accurate measurements of it are needed, through geological investigations over the entirety of the affected region. The results can be used to plan a strategy for preventing the tunnel from serving as a possible path of contamination from the upper aquifers, commonly used by individual wells and municipalities to those below the aquatard, commonly used by the local municipalities. During construction activities, precautions are needed to guarantee that spills of chemicals, including lubricants and fuels from the construction equipment, are captured before they enter the groundwater. The downward slope presents special considerations in this regard that should be addressed. It is believed that this problem can be readily solved by conventional spill prevention and control measures, perhaps included in harmony with measures taken to prevent equipment from rolling downhill (see Section III.B).

\section{Occupational Safety During the Operation of the Facility}

A. "Ordinary" Occupational Safety Hazards

The occupational safety hazards encountered at all other large particle accelerator facilities will be found in this facility. In this section, the focus is on the issues that have been encountered before, at Fermilab and elsewhere. These have been successfully addressed by well-known techniques and are simply listed here, along with the corresponding safety and health needs, for completeness:

- The project will use high current electrical circuits in the magnets on a large scale. Present techniques in managing power distribution and providing means to effectively lock out supplies should be adequate to address the electrical hazard.

- Radiofrequency (RF) generation and distribution equipment will be used extensively. Present techniques for controlling possible exposures to non-ionizing radiation should be sufficient.

- Large amounts of cables in cable trays will be installed. Current methods for addressing fire protection concerns should be adequate.

- Long tunnels will be present. There is a need to adequately address Life Safety Code/fire protection issues to assure adequate provisions for egress and adequate means of prevention of and response to fires.

- There will be movements and alignment of large, heavy components. There is a need to include considerations related to ease of movement of equipment in the design to facilitate the prevention of injuries.

Nearly all of these issues can be readily addressed by applying the present collective experience to the design at an early stage. 


\section{B. Novel Occupational Safety Hazards}

This section is directed to those occupational safety hazards that are not generally encountered at accelerator facilities. These will all require consideration in the early planning stages in order to be addressed in an efficient manner.

\section{i. $\quad$ Large Scale Use of Cryogens}

This facility requires the extensive use of superconducting materials and cryogenics in both magnets and RF structures. While these technologies are relatively new, a number of accelerators world-wide have developed techniques adequate for addressing them. At Fermilab, the main attention has historically been devoted to superconducting magnets while at the Jefferson Laboratory the focus has been on superconducting RF cavities. Portions of these cryogenic systems will be deep underground, at the lower end of the Muon Storage Ring and on large slopes. Provisions will need to be made for the safe release of cryogens to the surface both during normal operations and in the event of quenches. Both institutions have developed mechanisms for using skilled engineers to independently review such systems for safety during the design and commissioning stages. The result has been the development of a number of standard engineering practices to mitigate both direct cryogenic hazards and the accompanying oxygen deficiency hazards (ODH). This general approach, if taken, should adequately address these hazards at the Neutrino Source.

\section{ii. $\quad$ Ionization Cooling Region}

The innovative proposal to use ionization cooling presents some novel hazards. The use of liquid hydrogen $\left(\mathrm{LH}_{2}\right)$ has, for now, been selected over other options, some of which involve hazardous or toxic materials. To set the scale, Figure 4 shows the layout of two $\mathrm{LH}_{2}$ along with their adjacent RF cavities and solenoids. While this choice may be preferred from environmental protection and industrial hygiene standpoints due to the lack of the potential for spills or exposures to hazardous or toxic materials, the fire/explosion hazard represents an important consideration. In the past, Fermilab instituted stringent review procedures using both internal and external of considerable distinction to manage $\mathrm{LH}_{2}$ hazards for comparable volumes applied to bubble chambers, notably the 15 Foot instrument. Smaller scale reviews were employed for $\mathrm{LH}_{2}$ targets used in various experiments. The $\mathrm{LH}_{2}$ systems being considered for the Neutrino Source are of a size not seen at Fermilab since the completion of the bubble chamber experimental physics program. The $\mathrm{LH}_{2}$ cells will be interleaved with $\mathrm{RF}$ structures and magnets that apply a great deal of electrical energy. Additionally, considerable energy will be deposited by the muons in the $\mathrm{LH}_{2}$ itself. In view of these considerations, a recommended approach would be to convene a review committee of qualified individuals at the earliest reasonable state in the design. Under the most optimistic scenarios, a long period of time will elapse between the end of operations of 15 Foot Bubble Chamber and commencement of operations of the Neutrino Source. 


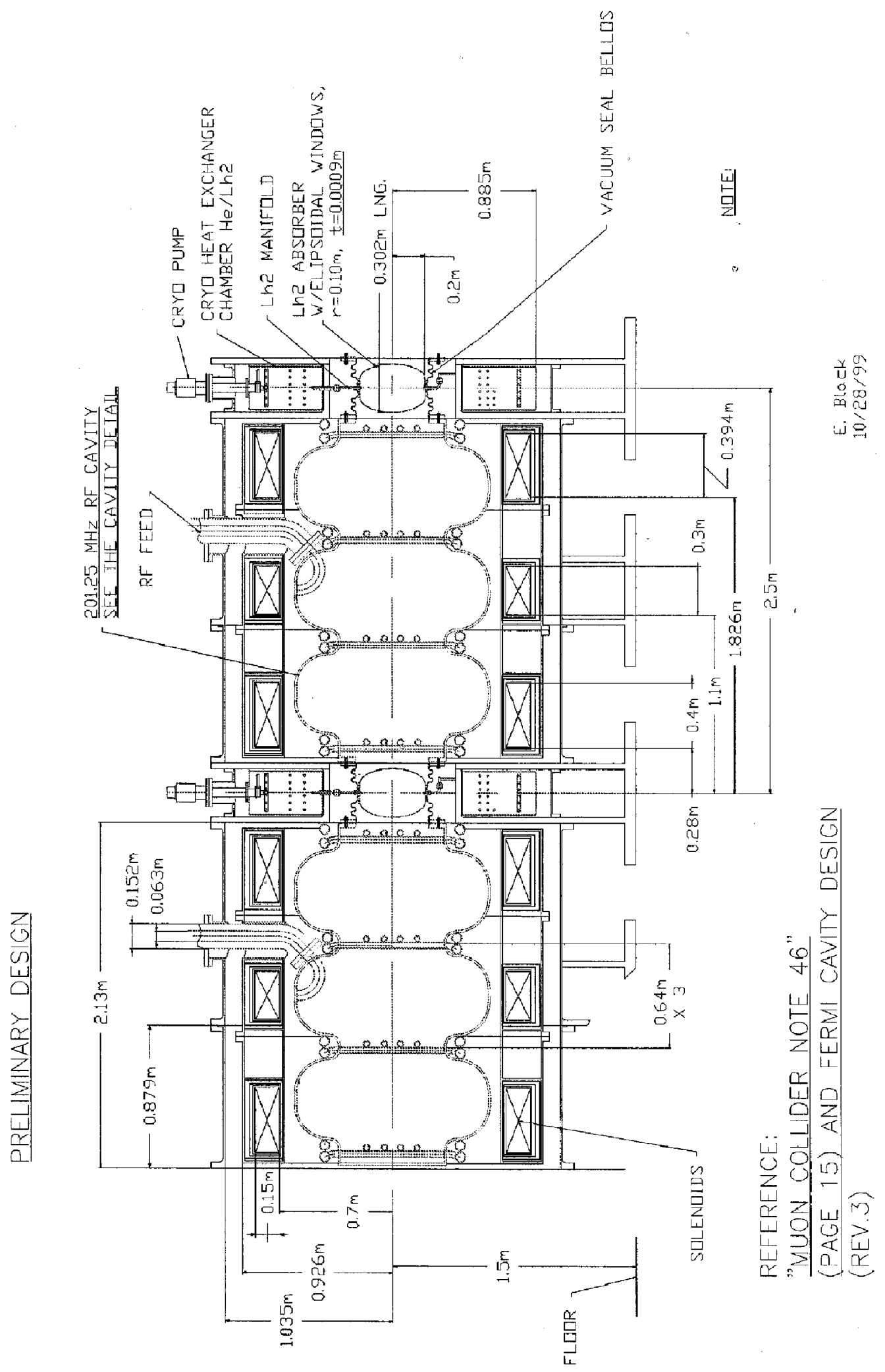

Figure 4 Longitudinal cross section of two liquid hydrogen $\left(\mathrm{LH}_{2}\right)$ cells along with their adjacent $\mathrm{RF}$ cavities and solenoids. 
In view of this, it might serve the project well to garner the expertise of the remaining Fermilab staff members familiar with bubble chamber operations and the accompanying safety measures. With proper care attention given to this matter in the design stage, continued throughout operations, these issues can be addressed in a straightforward manner.

\section{iii. $\quad$ Muon Storage Ring Life Safety (Egress) Considerations}

The MuSR constitutes a long tunnel with an egress point at each end. The east (upper) end is near the surface and can be classified as an "ordinary" egress point. The west (lower) is rather far distant, and deep in the ground. At the lowest point in the present concept, at the west end of the lower Near detector Hall, an emergency egress shaft including an elevator is included. At the lower end of the storage ring proper, another access shaft along with a safe room and a cryogenics plant is planned. The fire protection/egress considerations of this configuration will need to be reviewed by a qualified fire protection professional for adequacy. Plans will need to be made for the evacuation of any injured personnel through the sloped arcs. The experience of other underground structures and mines as well as that gleaned from the planning process for NuMI should lead to successful solutions of these problems.

\section{iv. $\quad$ Muon Storage Ring Slope Hazards}

The steep slope of the MuSR presents unique hazards during construction as well as operation. The surface of the finished floor should be made sufficiently rough, or be grated, to provide good traction to individuals wearing ordinary shoes. Gutters should be provided to provide drainage of water seepage to the large sump pits at the lower end. They might also be designed to retard the downhill movement of rolling items. One has to also worry about heavy equipment, accelerated by gravity, rolling down the tunnel. An idea that might address this, and other considerations, is to arrange the gutters in a spiral fashion, regularly crossing the tunnel to direct such items toward the walls. Regular tie-down points for heavy items of equipment could also be provided. These problems can be solved if they are addressed early in the design process.

\section{Ionizing Radiation Safety During Operation of the Facility}

\section{A. Proton Driver}

\section{i. $\quad$ Prompt Radiation Shielding}

The Proton Driver and the Neutrino Source Target Station will require massive amounts of hadron shielding similar in scale and type to that of other proton accelerators in this energy regime. In this energy domain, shielding against neutrons sets the dimensional scale. The glacial till at Fermilab has a typical density of $2.25 \mathrm{~g} \mathrm{~cm}^{-3}$. Detailed calculations made using MARS (Mo 00a) have determined that a shield of approximately 29 feet (8.8 meters) of soil lateral to the beam will achieve a dose equivalent rate of $1 \mathrm{mrem}$ if the entire beam is lost in a localized region of the synchrotron for one hour. These dimensions are familiar to designers of proton 
accelerators at Fermilab and elsewhere. While the exact details of the shielding of the target station are still not known, it is clear that suitable combinations of steel, concrete, and earth shielding can meet the standard criteria for above ground shielding at Fermilab. At $16 \mathrm{GeV}$, the range of the muons of maximum energy is less than 30 meters of earth. Due to this fact, and given the forward-peaking due to production kinematics, the radius of curvature of the synchrotron, and the shielding needed to attenuate the neutrons, any muons produced by stray beam loss should be ranged-out and hence of no consequence. Thus, the shielding against the prompt radiation hazards is well-understood and can be addressed by conventional means.

The transport of beam from the synchrotron to the Target Station poses no peculiar problems with respect to prompt radiation shielding. Provision for the shielding of "stray", large-angle muons, not captured into the muon beam ensemble, should be provided downstream of the target.

\section{ii. $\quad$ Residual Radioactivity of Components}

The Proton Driver, under maximal operation, will handle up to 40 times the beam power of the present Fermilab Booster (Ch 99). As is well known, in the high energy region, most, but not all, of the radiation effects scale roughly with the beam power. The present Fermilab Booster already presents some problems in its servicing with respect to residual radioactivity at certain key loss points. The handling of the additional beam power to be encountered in the Proton Driver is already receiving careful attention. Calculations already performed have determined that a loss of 1 watt meter ${ }^{-1}$ will result in a residual dose equivalent rate of $100 \mathrm{mrem} \mathrm{hr}^{-1}$ after 30 days irradiation and 4 days cool down (Ch 99). This dose equivalent rate is rather high for effective maintenance work, especially if one desires shorter cooling periods. This particular calculation was performed for a lattice that does not include a collimation system. Such a collimation system could greatly localize the losses. Beam losses in the synchrotron can also produce soil activation. Efforts should continue to better understand, and minimize such losses of beam both from the standpoint of component activation and its effect on maintenance activities and also with respect to soil and groundwater activation.

The transport line to the target station can likely be made relatively "clean" (i.e., free of beam loss) through suitable matching of collimation with aperture.

\section{iii. $\quad$ Residual Radioactivity at the Target Station}

Given the high beam power, the residual activation of the Target Station merits special attention. The present concept calls for the use of superconducting magnets in this region as well. The radioactivation of cryogenic systems has been uncommon at Fermilab, but the hazards can be addressed by existing means. Activation calculations have already been made (Mo 00a). The residual activity levels to be found in the Target Station are not presently known in detail, but will be large, of the order of a few krads $\mathrm{hr}^{-1}$. There is likely to be significant activation of water used to cool the non-cryogenic components as well. These activation levels can be readily calculated in detail in a straightforward manner as the design proceeds. It is clear that remote 
handling capabilities of the style used by other facilities such as the Los Alamos Meson Physics Facility (LAMPF) and being planned for the Spallation Neutron Source (SNS) at the Oak Ridge National Laboratory will be needed. The present detailed studies ongoing to develop the designs for the NuMI and MiniBooNE projects should be useful in this regard. Collaboration with SNS design work is especially encouraged. The need to provide for remote handling must be incorporated into the design at a very early stage in order to result in acceptable radiation doses to maintenance personnel during operations.

The target itself poses particular problems. If the choice of the target is to be solid carbon, the number of long-lived radionuclides that can readily be produced is limited due to the low atomic number. ${ }^{3} \mathrm{H}$ (12.3 year half-life), ${ }^{7} \mathrm{Be}$ (53.6 day half-life) and ${ }^{11} \mathrm{C}$ (20.3 minute half-life), are expected to be the dominant radionuclides produced. ${ }^{11} \mathrm{C}$ is of limited importance since it is sensible to wait for that nuclide to decay. A preliminary calculation has found that each $16 \mathrm{GeV}$ proton produces 1.5 nuclear interactions (i.e., "stars") in a carbon target (Mo 00a). Using the standard values of the total inelastic cross section (PDG 96) for high energy interactions with carbon along with the production cross sections for the nuclides ${ }^{3} \mathrm{H}$ (Ko 93), ${ }^{7} \mathrm{Be}$ and ${ }^{11} \mathrm{C}(\mathrm{Ba} 69)$, one can estimate the total activities of these radionuclides in the target. With $1.5 \mathrm{MW}$ beam, one can crudely calculate that at saturation (i.e., after a run that is long in duration compared with any of the half-lives). The result is about $1540 \mathrm{Ci}(57 \mathrm{TBq})$ of ${ }^{3} \mathrm{H}, 1020 \mathrm{Ci}(3.8 \mathrm{TBq})$ of ${ }^{7} \mathrm{Be}$, and $2055 \mathrm{Ci}(76 \mathrm{TBq})$ of ${ }^{11} \mathrm{C}$. These are the principal radionuclides produced in a carbon target of significant lifetime. The gamma-emitting ${ }^{7} \mathrm{Be}$ will be the major contributor to residual exposure rates. Taking the branching ratio of $10.4 \%$ for the ${ }^{7} \mathrm{Be}$ gamma-ray emission into account, and very crudely assuming the target to be a "point" source, the absorbed dose rate at 1 meter would be about $21 \mathrm{rad} \mathrm{hr}^{-1}\left(0.21 \mathrm{~Gy} \mathrm{~h}^{-1}\right)$. This represents a significant hazard, but one that can be addressed adequately using existing technologies for remote handling. Other Target Station components can be handled similarly. Consultation with other facilities that have had to address the handling of components of similar activity levels should be done to plan carefully for maintenance activities.

The Department of Energy has developed special requirements applicable to nuclear facilities that are specified in DOE's Regulations, Orders, and associated Standards (e.g., DOE 92). In particular, nuclear facilities are subject to levels of safety analysis, quality assurance, and training requirements that can be significantly more stringent than those that have typically been applied to accelerator facilities. The present DOE definition of nonreactor nuclear facility means, "... those activities or operations that involve radioactive and/or fissionable materials in such form and quantity that a nuclear hazard potentially exists to the employees or the general public..."; further, "Incidental use and generating of radioactive materials in a facility operation (e.g., check and calibration sources, use of radioactive sources in research, and experimental and analytical laboratory activities, electron microscopes, and X-ray machines) would not ordinarily require the facility to be included in this defnition. Accelerators and reactors and their operations are not included". It seems rather clear that the Neutrino Source pion production target does not qualify as a nuclear facility. 
However, there are alternate interpretations of these requirements afoot that indicate the possession of radionuclides in a particular facility above certain thresholds, specified in DOE Orders and Standards (DOE 92), can result in that item being classified as a nonreactor nuclear facility. For ${ }^{3} \mathrm{H}$ this threshold is $1.6 \times 10^{4} \mathrm{Ci}$, for ${ }^{7} \mathrm{Be}$ the threshold is $1.48 \times 10^{4} \mathrm{Ci}$, and for ${ }^{11} \mathrm{C}$ the threshold is $3.6 \times 10^{4} \mathrm{Ci}$. For a "mixture", such as found in an activated target, one must sum the ratios of the individual activities to its particular threshold. If the sum exceeds unity, then the threshold has been exceeded. For a carbon target, the thresholds are not exceeded for a $1.5 \mathrm{MW}$ beam, based upon this approximate estimate. However, the standards can be interpreted to apply to the entire target station, not just the target itself. The situation might be different for a target of higher atomic number and, of course, for larger proton beam powers. More accurate calculations should be done and any remaining questions about the status of the facility as a nuclear facility resolved at the earliest possible time. The designation of the target as a nonreactor nuclear facility would add some stringent requirements. If that designation were to be made, it might be advisable to segregate the operation of the target from that of the rest of the facility to the extent possible. The Laboratory continues to monitor the ongoing development of DOE requirements on this topic.

Unlike the situation encountered at other neutrino facilities of higher energies, there is no hadron absorber at the "far" end of the decay pipe that should be the site of appreciable radioactivation. This feature is a benefit of the choice of energy, since essentially all of the pions and kaons ahave time to decay in transit at these lower energies.

\section{iv. Airborne Radioactivity}

The production of airborne radioactivity in the vicinity of the Target Station will constitute the dominant source of airborne radioactivity in the facility. The presence of continuous vacuum through the synchrotron and the need to carefully control the losses in the lattice should also minimize the production of airborne radioactivity. Recent developments on the NuMI and MiniBooNE projects have made it clear that the control of the airborne radioactivity is a significant design consideration. At this early stage of conceptual design, a comparison with the more advanced work on the NuMI Target Station may be useful, for illustration, since the beam powers to be handled are comparable and an analysis of the production of airborne radionuclides has been documented (Gr 99). The NuMI Target Station will operate at a beam power of 0.404 MW. It has been calculated that operations of NuMI at that level of beam power will release a total of about $15 \mathrm{Ci}(555 \mathrm{GBq})$. This is dominated by $5 \mathrm{Ci}(185 \mathrm{GBq})$ of ${ }^{11} \mathrm{C}$ (half-life $=20.3$ min.) and $9.8 \mathrm{Ci}(363 \mathrm{GBq})$ of ${ }^{41} \mathrm{Ar}$ (half-life $=1.83$ hours). Such releases will result in a dose equivalent of $0.009 \mathrm{mrem}^{-1}\left(0.09 \mathrm{microSv}^{-1}\right)$ at the site boundary. While this level is small, it reflects the desire to be safely below a value of 0.1 mrem $(1$ microSv) in one year for the sum of the emissions from all sources at Fermilab. Above $0.1 \mathrm{mrem}$ in one year, stringent continuous monitoring requirements imposed by U. S. Environmental Protection Agency Regulations (CFR 89) are required to demonstrate that the regulatory limit of 10 mrem (100 microSv) in one year is not exceeded. In addition, if the level of $0.1 \mathrm{mrem}$ in one year is to be exceeded, then an application for approval to construct and a notification of startup must both, in proper sequence, 
be submitted to the U. S. Environmental Protection Agency. The NuMI results were achieved only by carefully designing the ventilation system to maximize the decay in transit from the point of production to the release stack. A conservative approach was taken with respect to NuMI in order to avoid compromising the operations of other facilities at Fermilab.

The conclusion to be drawn here concerning the Neutrino Source is that the airborne radionuclide emissions can be quite significant and should be addressed early in the design stage. The Laboratory must also decide which other facilities, especially target stations, might operate concurrently with the Neutrino Source and thus need to "share" in the "economics" of the allowable airborne radionuclide emissions.

\section{v. Radioactivity in Soil and Groundwater}

The calculation of the radioactivity produced in the soil around the Proton Driver and Target Station can be accomplished in a straightforward manner using current versions of Monte-Carlo shielding codes. It is likely that the bulk shielding of the Target Station will be driven nearly as much by the need to limit the activation of soil outside of the Target Station enclosure as by the control of above-ground prompt radiation levels. There is a great benefit of locating the Target Station in the glacial till rather than in the bedrock units.

Recent studies have found that the glacial till generally provides for very low hydraulic conductivities, which, when the gradients are included, results in a very slow migration downward of radionuclides produced in the soil to the nearest sources of drinking water, affording considerable time for decay in transit. However, before the exact location of the facility is irrevocably determined, detailed hydrogeologic studies should be conducted to determine the relevant parameters precisely, as they are known to vary over the Fermilab site. In view of the beam losses anticipated in the Proton Driver as well as the obvious losses of protons in the Target Station, these studies should address both parts of the facility in order to find the "best" place that maximizes protection afforded by the glacial till. They should be conducted at a very early stage to properly incorporate any necessary mitigation measures into the design. Guidance on "standard" methods of estimating potential groundwater calculations at Fermilab have been documented elsewhere (Co 94, updated in Co 99).

\section{B. Cooling Stages}

In the Cooling Stages, the collected muons from the pion decay will deposit considerable energy in the $\mathrm{LH}_{2}$ cells in the course of being "cooled". This energy will end up largely in the form of heat transferred to the hydrogen and dispersed by the refrigeration equipment. Given the low energy of the muons at this stage only energy loss by ionization is important, alternative energy loss mechanisms of pair production, nuclear interactions, and deep inelastic nuclear scattering contribute very little. Of course, some of the muons will decay during cooling. The electrons emitted in muon decays will interact with the surrounding materials and initiate electromagnetic showers. These will be limited in their spatial distributions, the sizes of which will be of the 
scale of a few radiation lengths. It should be straightforward to design shielding appropriate to containment of "stray" muons that might miss the cooling apparatus as well as the electromagnetic cascades induced by the decay electrons. Several existing Monte-Carlo codes are adequate to provide accurate calculations of this effect. The forward-peaked nature of the muon field should minimize the lateral extent of the shielding necessary.

The production of induced radioactivity in these stages is also severely limited by the energy, and the fact that leptons are the only particles present.

\section{Muon Acceleration Stages}

Radiological considerations for the Muon Acceleration stages are similar to those encountered in the Cooling stages. At the higher energy stages, the scale of the muon shielding required will increase, but even the final muon energy is still relatively small given the fact that the mean range of a $50 \mathrm{GeV}$ muon in soil is only about 109 meters. Likewise the size and importance of the electromagnetic cascades produced by the decay electrons will be progressively larger as the energy increases. Locating the facility below grade should facilitate the provision of the necessary shielding. Again, present methods of performing the necessary calculations are available. Some radioactivation could be expected, but at levels much smaller than those to be experienced in the Proton Driver and Target Station.

\section{Muon Storage Ring}

\section{i. $\quad$ Control of Radiation Dose Due to Neutrinos}

The principal, and most unusual, radiation consideration pertaining to the Muon Storage Ring is that due to the neutrinos produced by the decaying muons. Obviously, the design of the entire facility is optimized toward the production of high fluence of neutrinos in the intended direction downward (westward). This also results, unavoidably, in a similar stream of neutrinos in the upward direction. The methods for calculating radiation dose equivalent from neutrino fluence have been described elsewhere (Co 97 and Mo 99).

Some detailed understanding of the pertinent requirements must preface further discussion. The Department of Energy has specified the annual limits on the radiation dose equivalent that can be received by occupational workers and members of the public (see Regulation 10 CFR 835 in WSS 99 and DOE 93). These limits, in all situations expressed to date, pertain to the dose equivalent delivered to people or to locations where people could reasonably be. For example, it is quite plausible for someone to be living in a house at ground level near the Fermilab site boundary. For individual members of the public, the primary limit is $100 \mathrm{mrem}(1 \mathrm{mSv})$ in a year, not including man-made, medical, or enhanced natural radioactivity. This limit is intended to apply to all sources of radiation exposure that a person might receive, even from non-DOE manmade sources. Special reporting requirements apply when the annual dose equivalent received by an individual exceeds $10 \mathrm{mrem}(0.1 \mathrm{mSv})$ in a year. DOE has expressed the view 
that nonoccupational annual doses to real persons are not expected to exceed a few mrem in a year. As a convenient reference point, the average annual radiation dose equivalent received by individuals living in the United States is about 360 mrem (3600 microSv) (NCRP 87). Of this exposure, about 300 mrem (3000 microSv) is due to natural sources, including exposure to radon indoors.

Figure 5 shematically displays the "lobe" of neutrino radiation expected due to neutrinos produced by muon decays in the downward (westward) straight section of the MuSR. The parameters $\mathrm{L}$ and $\mathrm{R}$ describe the length and maximum radius of a chosen contour of equal annual dose equivalent. L is measured from the end of the MuSR straight section along the centerline of the neutrino trajectory, a natural axis to use in this discussion, while $\mathrm{R}$ is measured perpendicular to the neutrino trajectory. This axis makes an angle of $13.16^{\circ}$ downward from the earth's surface. Cylindrical symmetry should hold about this axis for this radiation field. Mokhov has calculated these radiation fields and has plotted the results for different contours of interest in Figure 6 (Mo 00b). A similar radiation field will penetrate the surface due to muon decays in the upward (eastward) straight section of the MuSR centered about the axis of the upward (westward) MuSR straight section.

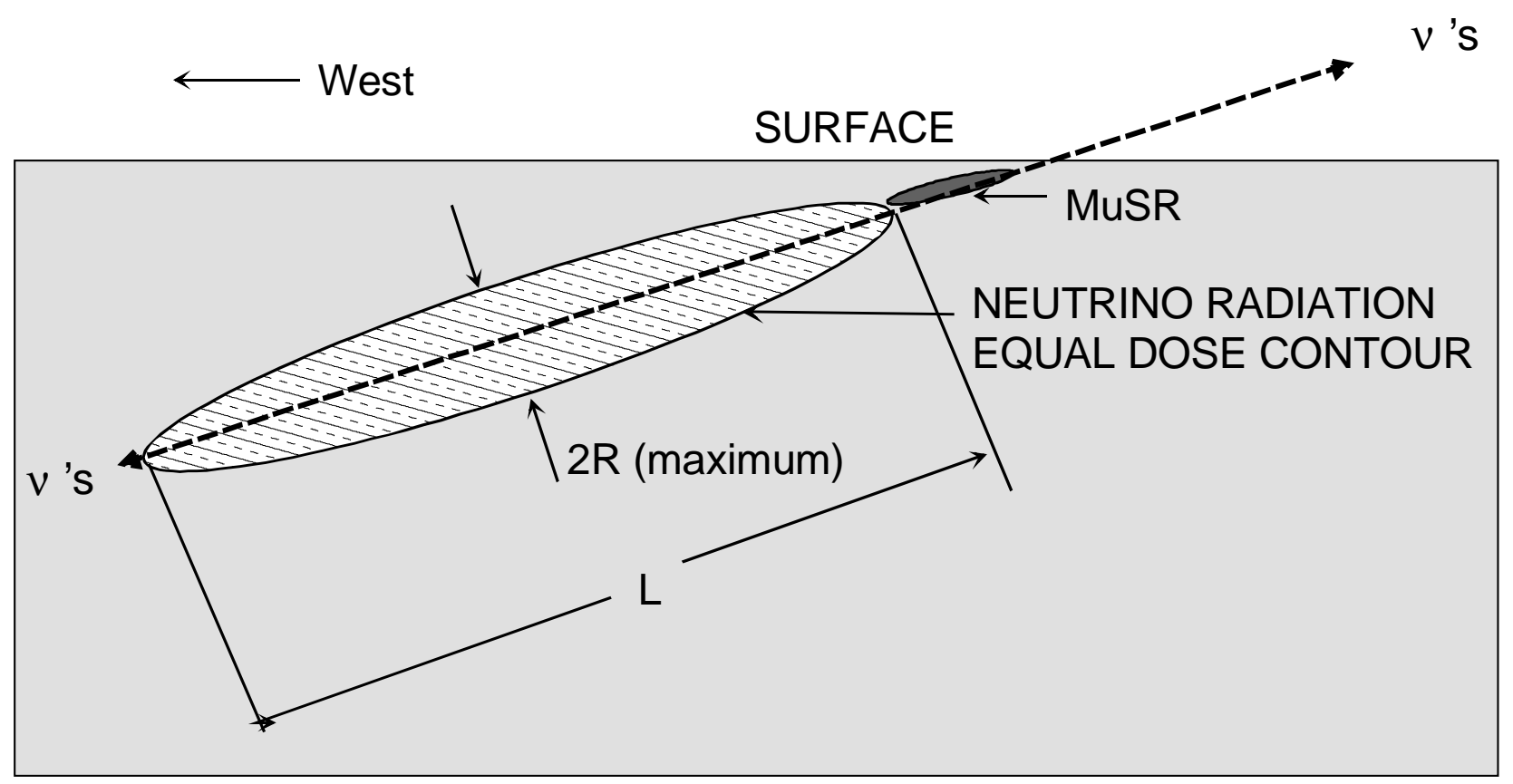

Figure 5 Schematic representation of the neutrino radiation fields due to muon decays in the MuSR. The gray region is the earth while the cross-hatched region is a schematic representation of the region inside of a selected contour of equal dose equivalent due to the neutrinos resulting from downward muon decays. A similar neutrino radiation lobe is to be found in the upward direction due to upward muon decays in the other straight section of the ring. The parameter L describes the intersection of this isodose contour with the center line of the neutrino trajectory while $\mathrm{R}$ is its maximum radial extent. The actual contours are more forward-peaked, and narrower than is this symbolic ellipse. However, symmetry about the center line of the neutrino trajectories is expected. 


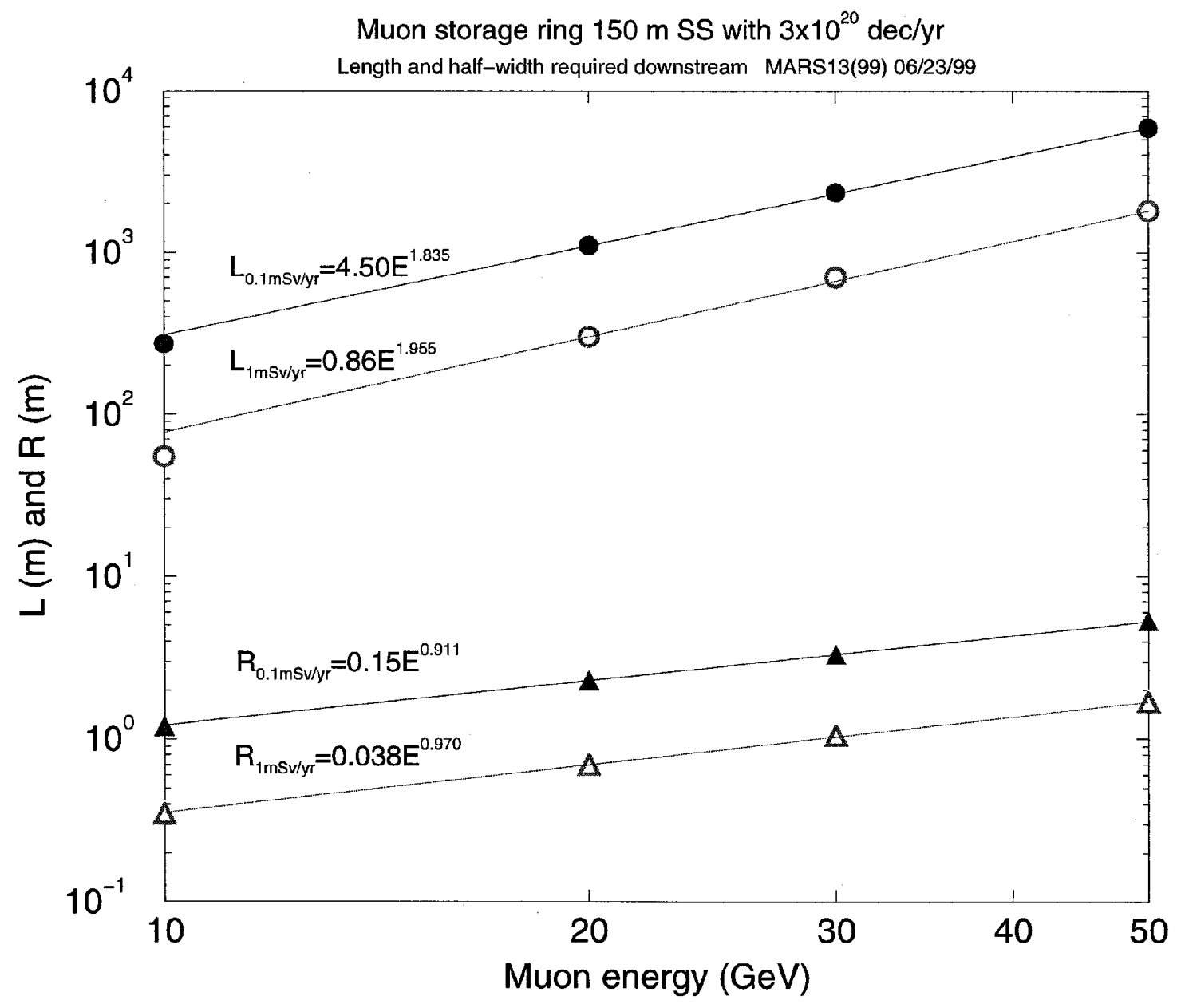

Figure 6 Results of calculations of the values of $L$ and $R$ (see Figure 5) which describe the neutrino radiation field resulting from muon decays from one Muon Storage Ring straight section ("SS") as a function of muon energy energy. These are presented for two different annual dose equivalents, $1 \mathrm{mSv} \mathrm{y}^{-1}(100$ mrem $\left.\mathrm{y}^{-1}\right)$ and $0.1 \mathrm{mSv} \mathrm{y}^{-1}\left(10 \mathrm{mrem} \mathrm{y}^{-1}\right)$. The symbols denote the actual calculations of Mokhov (Mo $00 \mathrm{~b})$. The results of power law fits are also shown. 
First, consider the neutrino radiation due to the decays of muons in the downward straight section of the MuSR, the situation shown in Figure 5. It is highly unlikely that the neutrino radiation from decays in this region will deliver a radiation exposure to any real, or hypothetical persons because of the depth of this region below the earth's surface. One should consider the effects at $50 \mathrm{GeV}$, the energy for which the neutrino radiation is the most significant. Working directly from the results shown in Figure 6, on this axis, a dose equivalent rate of 100 mrem per year of Neutrino Source operations is achieved at a distance of 5915 feet (1803 meters). Beyond this point, the annual dose equivalent will be less. A dose equivalent rate of 10 mrem per year of Neutrino Source operations is found at a distance of 19,356 feet (5900 meters) on this axis, measured from the end of the MuSR straight section. Neglecting the curvature of the earth, the former location is 1345 feet (410 meters) below the surface while the latter is 4407 feet (1343 meters) below the surface. The maximum radius of the 100 mrem per year contour is at 5.54 feet (1.69 meters) laterally from the centerline axis while that of the 10 mrem per year contour is 17.35 feet (5.29 meters) from this axis. Thus, this radiation field is extremely forward peaked and is of no consequence at all on the surface.

Figures 7 and 8 show how this can be accommodated underneath the existing Fermilab site. Figure 8 , in particular, shows that the 100 mrem per year contour can be accommodated entirely underneath the existing Fermilab site with allowance of a reasonable degree of freedom of siting provided to accommodate other considerations. If the MuSR is located near the eastern edge of the Fermilab site, even the 10 mrem per year contour can be located underneath the existing site. Clearly, given the great depths at which this radiation lobe is found, it is inconceivable that any person could be exposed to radiation due to the decays of muons in the downward straight section. A comment should also be made that at these levels of neutrino fluence, given the small interaction cross sections involved, the radioactivation of soil and groundwater is insignificant. Further detailed calculations should be performed to verify this conclusion.

The parameters associated with these contours can be used to estimate the dose equivalent to be found in the experimental hall to be located at SLAC/LBNL, $2700 \mathrm{~km}$ downstream on the centerline axis. Making the reasonable assumption of a simple inverse square law dependence, and taking the intersection of the 10 mrem per year contour with this longitudinal axis as a scaling length, a dose equivalent rate of about $4.8 \times 10^{-5} \mathrm{mrem}(0.48 \mathrm{nSv})$ per year is found at the experiment. A similar result is obtained using the intersection of the 100 mrem per year contour to set the scale. This dose equivalent is extremely small compared with the average annual dose equivalent in the United States due to natural sources of approximately 300 mrem (3000 microSv) due to natural sources (NCRP 87).

Now one must consider the decays of muons in the upward straight section of the MuSR. These present somewhat different neutrino radiation problems. The neutrinos resulting from these decays will have penetrated a soil shield before emerging from the earth centered about the centerline axis. This axis makes an angle of $13.16^{\circ}$ upward relative to the surface. The shapes of 


\section{WEST BOUNDARY CONSTRAINTS}

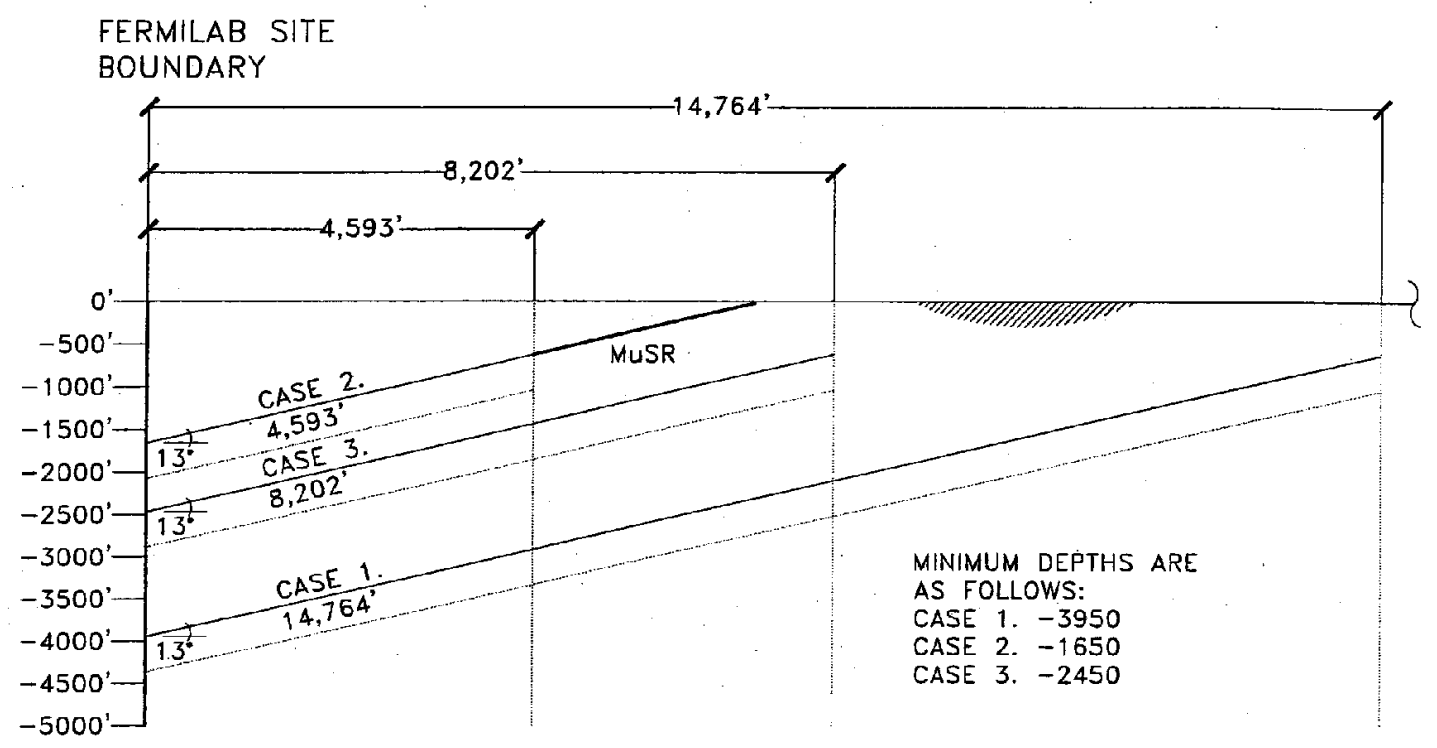

EAST BOUNDARY CONSTRAINTS

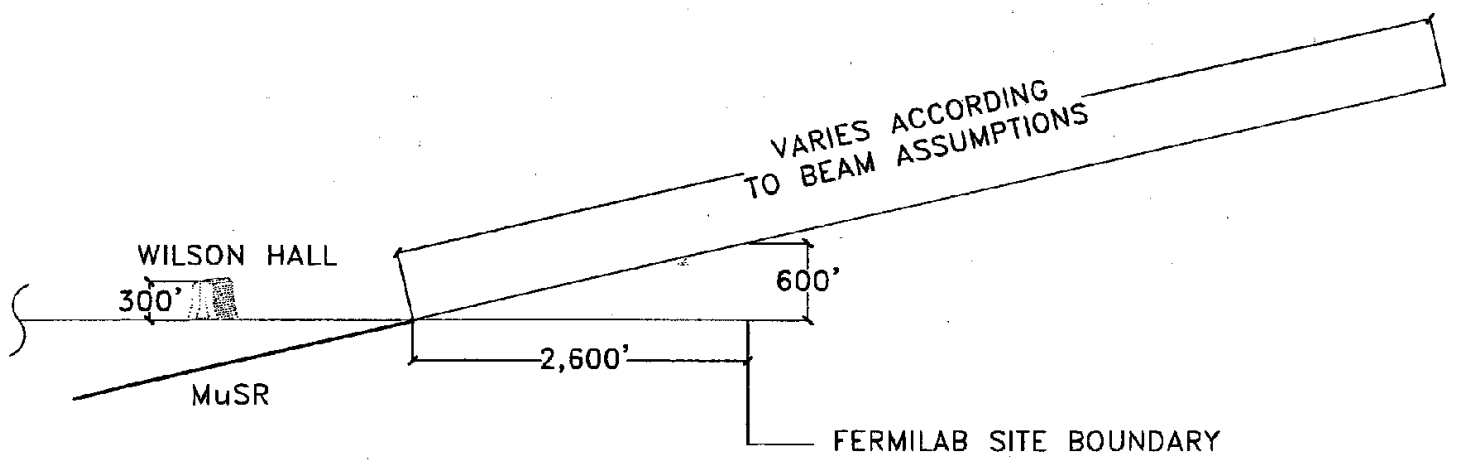

\begin{tabular}{lllll|}
\hline LIMITS: & \multicolumn{2}{c}{ mrem/year } & \multicolumn{2}{c|}{ CONTROL CYL. } \\
CASE 1. $50 \mathrm{GeV}$ & 10 & $4.5 \mathrm{KM}$ & RADIUS $=4.0 \mathrm{M}$ \\
CASE 2. $50 \mathrm{GeV}$ & 100 & $1.4 \mathrm{KM}$ & RADIUS $=1.2 \mathrm{M}$ \\
CASE 3. $30 \mathrm{GeV}$ & 10 & $2.5 \mathrm{KM}$ & RADIUS $=5.0 \mathrm{M}$ \\
\hline & \multicolumn{3}{c}{ GTE } \\
\end{tabular}

Figure 7 East-west vertical cross section through the Fermilab site showing the radiological constraints on siting explained in the text. These are based on calculations of the annual dose equivalent due to neutrinos originating from muon decays in the MuSR straight sections due to Mokhov (Mo 00b). 


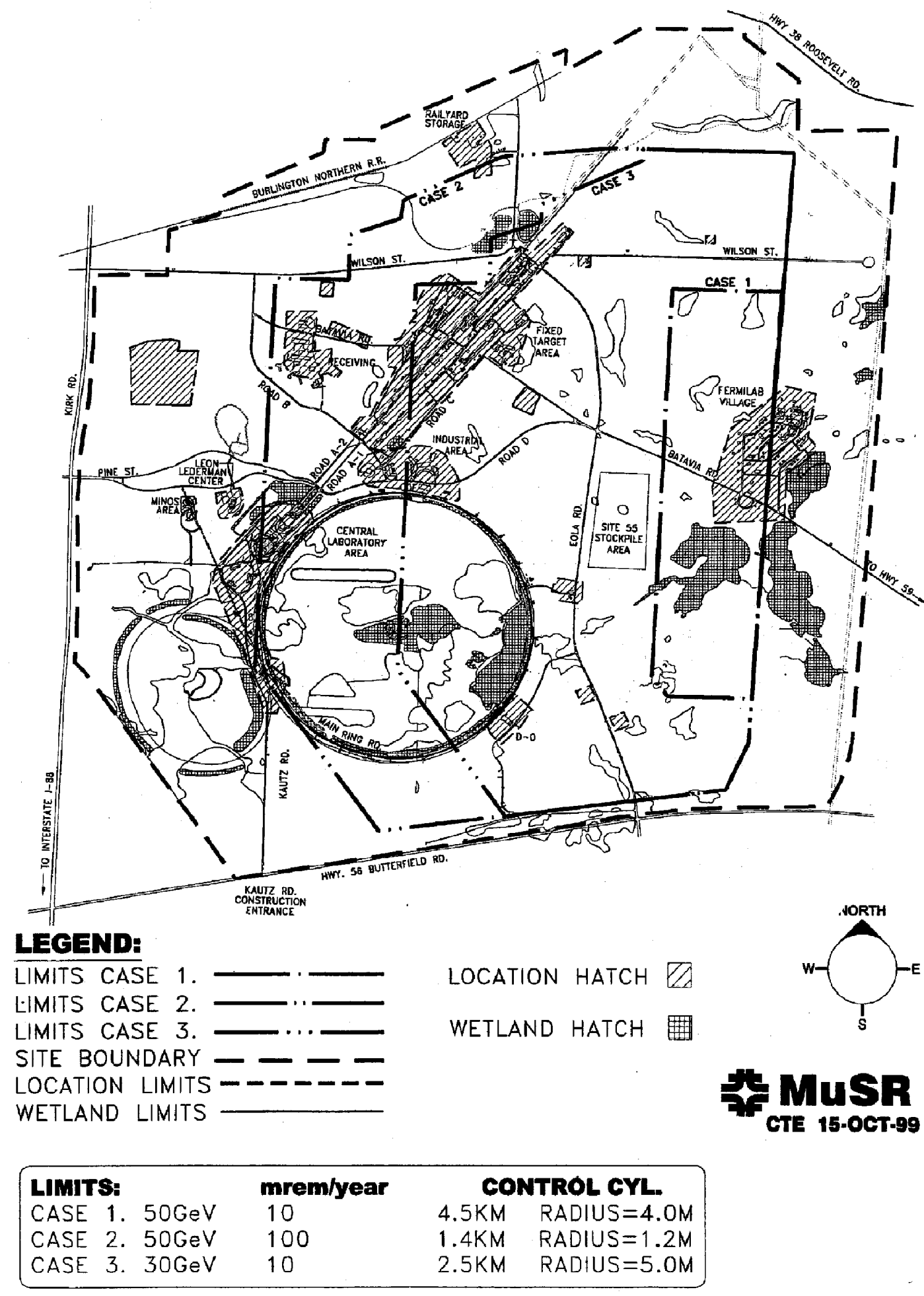

Figure 8 Map of the Fermilab site that displays the siting constraints for locating the MuSR explained in the text. These are based on calculations of the annual dose equivalent due to neutrinos originating from muon decays in the MuSR straight sections due to Mokhov (Mo 00b). 
these neutrino radiation lobes are the same as those discussed for the downward straight section, of course. Customarily, steady-state dose equivalent rates in fenced outdoor areas at Fermilab have been limited to $100 \mathrm{mrem}(1 \mathrm{mSv})$ per hour. It is noted that the specified operational year of the Neutrino Source of $2 \times 10^{7} \mathrm{sec}$ amounts to 5555 hours. Thus, following present practice, the annual dose equivalent that could be delivered in such an outdoor, fenced area could be as large as $5.7 \times 10^{5} \mathrm{mrem}$. If one uses the intersection of the $100 \mathrm{mrem}$ per year contour with the axis of the enclosure and applies a simple inverse-square law approximation, one finds that $5.7 \times 10^{5}$ mrem $\mathrm{y}^{-1}$ is achieved after 24.2 meters (79.4 feet) from the end of the enclosure. This corresponds to a vertical depth below the surface of the high end of the enclosure of 5.5 meters (18.0 feet). This depth is generally compatible with the elevations being proposed for the lower energy components of the facility. The choice of a greater depth, of course, reduces this problem. For example, if the depth of this point on the MuSR is chosen to be 10 meters (32.8 feet), the maximum dose equivalent rate in this fenced outdoor area is reduced to $1.69 \times 10^{5} \mathrm{mrem}(1.69 \mathrm{x}$ $10^{6}$ microSv) year or 30.36 mrem (303.6 microSv) per hour.

The offsite dose equivalent in the upward-going lobe must be considered. The maximum radius of the 10 mrem contour is 17.35 feet (5.29 meters). For sake of discussion, one can assume that no building taller than 500 feet (152 meters, about 40 stories) is likely to be built adjacent to the eastern boundary of the Fermilab site during the lifetime of this facility. To exclude delivery of greater than 10 mrem to the hypothetical full-time residents of such a building, the axis of the extension of the upward straight section must be at least 517 feet (157 meters) above the surface at the site boundary. The application of trigonometry tells us that the exit of the axis from the surface must be at least 2211 feet (674 meters) inside of the site boundary as a consequence. It is unlikely that commercial or general aviation aircraft would be present in this radiation for sufficiently long periods to encounter significant radiation exposures. The values discussed above are approximate, but in good agreement with the more detailed calculations of Mokhov (Mo 00b) that were used to provide the siting constraints shown in Figures 7 and 8.

\section{ii. $\quad$ Other Radiation Sources}

The bombardment of the walls of the MuSR components will involve a nearly uniform irradiation by electrons. These electrons will be of sufficient energy to initiate electromagnetic cascades. The radiation effects of these cascades related to both equipment damage and to the production of radioactivity are readily calculable using several different Monte-Carlo codes. The electromagnetic cascades, as always, affect physical dimensions measured in multiples of the radiation lengths of the materials involved. Such calculations have been reported elsewhere by Mokhov (Mo 00c). These calculations are important to determine energy deposition in the superconducting magnets and to provide a basis for the choice of materials to shield the critical parts of these beam elements. Residual dose equivalent rates due to these cascades will be small, less than about $1 \mathrm{mrem} \mathrm{h}^{-1}\left(10 \mathrm{microSv} \mathrm{h}^{-1}\right)$ after a 30 day irradiation, 1 day cooldown. 
It is feasible for the muons stored in the MuSR to be catastrophically lost in the event of a sudden power outage or some other failure of the magnets. However, given the orbit time of 6 microseconds and the likely decay time constants of the magnets, the loss of the muons during such an event would be distributed over many turns and large portions of the ring. Only a tiny fraction of them would be directed in a manner in which they penetrate the surface. Further calculations of the radiation fields that might emerge from the upward straight section of the ring should be made to demonstrate this.

It is nearly certain that the near detector halls will be exclusion areas during operations due to neutrinos as well as the other background sources that are unavoidably present.

\section{Non-Radiological Environmental Protection Issues During Operation}

A. Proton Driver, Target Station, Cooling Region, and Muon Acceleration Linacs

The issues are straightforward ones related to the control of non-radioactive wastes. Clear efforts should be made to prevent the creation of regulatory mixed wastes. Written plans should be developed to control any potential spills of hazardous chemicals effectively in a way that prevents environmental pollution. Provisions should be made for the effective management of surface water discharges in accordance with the current Laboratory policies and State and Federal environmental permits that may be in place. These considerations are quite similar to those encountered at other Fermilab facilities located in the glacial till and represent no problems that have not been solved before.

\section{B. Muon Storage Ring}

The location of the MuSR in aquifer units requires especially stringent protection against spills. It is also very important to continue to avoid the cross-connection of surface waters with the various aquifer layers and cross-connections between different aquifer layers. Control of surface water discharges is especially important here. Efforts must be made to assure that any pumping necessary to keep the enclosure dry does not create perturbations of local community or individual drinking water supplies. Careful attention to these problems during the design and construction phases should prevent occurrence of such a condition.

\section{Summary}

The Neutrino Source provides a number of challenges in the area of environment, safety, and health. Many of these have been encountered, and effectively addressed, at other accelerator facilities. Some of the problems are common to other recent projects undertaken at Fermilab and elsewhere that have resulted in the need to develop new methods to address them. This project raises a few new issues that must be addressed. It is concluded here that with adequate planning in the design stages, these problems can be adequately addressed in a manner that merits the support of the Laboratory, the Department of Energy, and the public. 


\section{Acknowledgements}

I would like to thank Rod Walton, Mary Logue, Bill Griffing, Alex Elwyn, and Kamran Vaziri, my colleagues in the Fermilab ES\&H Section, for their helpful comments. I should also recognize Norbert Holtkamp and David Finley for their clear presentations of the details of the conceptual facility under consideration here. Nikolai Mokhov was especially attentive to my needs by providing me with his latest calculations as they were performed.

\section{References}

Ba 69 M. Barbier, Induced Radioactivity, (North-Holand Publishing Company, Amsterdam and London, Wiley Interscience Division, John Wiley and Sons, Inc, New York, 1969).

CFR 89 United States Code of Federal Regulations, Title 40, Part 61, Subpart H, "National Emissions Standard for Hazardous Air Pollutants (NESHAP) for the Emission of Radionuclides other than Radon from Department of Energy Facilities", 1989.

Ch 99 W. Chou, "Proton Driver Study at Fermilab", Fermilab Report FERMILAB-Conf99/277, October 1999.

Co 94 J. D. Cossairt, "Use of a Concentration-Based Model for Calculating the Radioactivation of Soil and Groundwater at Fermilab", Fermilab Environmental Protection Note 8, December 1994.

Co 97 J. D. Cossairt, N. L. Grossman, and E. T. Marshall, "Assessment of Dose Equivalent Due to Neutrinos", Health Physics 73 (1997) 894-898.

Co 99 J. D. Cossairt, A. J. Elwyn, P. Kesich, A. Malensek, N. Mokhov, and A. Wehmann, "The Concentration Model Revisited", Fermilab Environmental Protection Note 17, June 1999.

DOE 92 U. S. Department of Energy, "Nuclear Safety Analysis Reports", DOE Order 5480.23, April 30, 1992. The classification criteria specified in this Order are provided in a DOE Standard, "Hazard Categorization and Accident Analysis Techniques for Compliance with DOE Order 5480.23, Nuclear Safety Analysis Reports", DOE-STD1027-92 Change Notice No. 1, September 1997. The criteria are augmented by additional radionuclides in LA-12981-MS, UC-940, "Table of DOE-STD-1027-92, Hazard 3 Threshold Quantities for the ICRP-30 List of 757 Radionuclides", Los Alamos National Laboratory Report, August 1995.

DOE 93 U. S. Department of Energy, "Radiation Protection of the Public and the Environment", DOE Order 5400.5, January 7, 1993. 
Gr 99 N. L. Grossman, D. J. Boehnlein, and J. D. Cossairt, "Production and Release of Airborne Radionuclides Due to the Operation of NuMI", Fermilab Report TM-2089, August 1999.

Ho 00 N. Holtkamp and D. Finley, editors, "A Feasibility Study of a Neutrino Source Based Upon a Muon Storage Ring", Fermilab Report, March 31, 2000, http://www.fnal.gov/projects/muon_collider/nu-factory/nu-factory.html.

Ko 93 A. Yu. Konobeyev and Yu. A. Korovin, "Tritium Production in Materials from C to Bi Irradiated with Nucleons of Intermediate and High Energies", Nucl. Instrm. and Meth. in Phys. Res. B82 (1993) 103-115.

Mo 99 N. V. Mokhov and A. Van Ginneken, "Neutrino Induced Radiation at Muon Colliders", presented at the 1999 Particle Accelerator Conference, New York, New York, Marcy 19-April 2, 1999, FERMILAB-Conf-99/067.

Mo 00a N. V. Mokhov, MARS calculations, private communication, January 2000.

Mo 00b N. Mokhov, private communication, January 2000.

Mo 00c N. Mokhov, "Radiation Load on Muon Storage Ring Magnets", Presentation given at Fermilab, January 25, 2000.

NCRP 87 National Council on Radiation Protection and Measurements, Ionizing radiation Exposure of the Population of the United State and Canada from Natural Background Radiation, NCRP Rep;ort No. 94, December 1987.

PDG 96 Particle Data Group, Review of Particle Properties, Physical Review D54, Part I (July, 1996).

WSS 99 "Fermilab Work Smart Standards Set", Fermi National Accelerator Laboratory, http://www-lib.fnal.gov/library/protect/worksmart.html, November 15, 1999. 